\title{
From the Anthropause to the Pandemic Turn: Emerging Directions in the Environmental Humanities in the Covid-19 Era
}

\author{
John Charles Ryan ${ }^{1}$ \\ https://orcid.org/0000-0001-5102-4561
}

${ }^{1}$ Southern Cross University \& Notre Dame University, Australia

\begin{abstract}
This article outlines current developments in the Environmental Humanities, abbreviated as $\mathrm{EH}$, that underscore its diversity and timeliness as scholars from manifold disciplines turn progressively more to human-nature issues in the Anthropocene epoch. Emerging in the last decade in particular, the twelve specializations outlined in this article are animal and plant studies; Arctic and Antarctic humanities, Asian environmental humanities, blue humanities, emergency humanities, empirical ecocriticism, energy humanities, extinction studies, medicalenvironmental humanities, paleoenvironmental humanities, Symbiocene studies, and wetland humanities. On the one hand, new areas such as the emergency humanities and medicalenvironmental humanities have gained momentum in response to the Covid-19 pandemic beginning in early 2020. On the other, some EH areas focus on alternatives to Anthropocene malaise and possibilities for human-nature justice. Understood as a transdisciplinary metafield - one that encompasses a spectrum of fields and tracks fluidly between disciplines - the Environmental Humanities aims to invigorate collective biocultural change and formulate radical approaches to sustainability at a time of rapid ecological decline worldwide.
\end{abstract}

Keywords: Anthropocene, deep time, environmental humanities, pandemic turn, transdisciplinary environmental research.

\section{Introduction: Rewilding the Urban}

In March 2020, during the coronavirus lockdown, a wild cougar was seen roaming the empty streets of Santiago, the Chilean capital city of six million people. Drawn out of Santiago's drought-stricken foothills by hunger and thirst, the mountain lion soon became disoriented in the eerily quiet urban maze. One month later, in Tel Aviv, Israel, jackals began scavenging for food in Yarkon Park, a popular urban recreational area that ordinarily receives sixteen million human visitors per year. Cougars in Santiago and jackals in Tel Aviv are but two examples of the 
unusual wildlife encounters in city environments reported in the news during the Covid-19 outbreak. Across the globe, the sudden decline in human mobility in 2020 led to a sharp drop in water, air, and noise pollution as well as poaching and trafficking. To describe the global slowdown of society, especially in relation to reduced petroleum-based travel, a team of ecologists proposed the term anthropause (Rutz). After centuries of satisfying the voracious industrial appetite of humankind, the coronavirus anthropause marked an unprecedented moment of biospheric respite. The ecologists behind the anthropause idea are part of the Covid-19 BioLogging Initiative, a consortium of researchers using the latest sensor technologies to measure changes in wildlife behavior in response to reduced human activity during the pandemic. Through the analysis of bio-logged data-for example, an animal's GPS location, speed of travel, and physiological condition - the initiative aims to advance understanding of humanwildlife interactions (International Bio-Logging Society).

For many, the appearance of wild animals in cities during the anthropause offers a hopeful sign of ecological rejuvenation. Statistics, however, reveal a different story. Consider, for instance, the most recent update of the International Union for Conservation of Nature (IUCN) Red List of Threatened Species, which calls attention to 31 recent extinctions. In total, the IUCN Red List enumerates 128,918 species, of which 35,765 - or $28 \%$ of all assessed species worldwide - are threatened with extermination, including $40 \%$ of all amphibians, $26 \%$ of all mammals, and 100\% of all freshwater dolphins (IUCN). Those recently declared extinct by the IUCN consist of 17 freshwater fish species endemic to Lake Lanao in the Philippines, 3 Central American frogs, and 9 Asian oaks.

In response to species extinctions, virus outbreaks, and other factors, the academic field of the Environmental Humanities has undergone a steady expansion over the last decade. Several 
foundational publications have contributed to defining the field as transdisciplinary, pluralistic, and emergent. Notable recent studies include The Environmental Humanities: A Critical Introduction (Emmett and Nye), Environmental Humanities: Voices from the Anthropocene (Oppermann and Serenella), and The Routledge Companion to the Environmental Humanities (Heise et al.). The field has also advanced of late through in-depth attention to invasion ecologies (Frawley and McCalman), river ecosystems (Kelly et al.), disability studies (Ray and Sibara), spatial injustice (Gladwin), the uncanny (Environmental Humanities and the Uncanny), and theology (Environmental Humanities and Theologies) in addition to crucial concerns of agency and time (Boschman and Trono). Regional and country-specific investigations include Italy and the Environmental Humanities (Iovino et al.) and Chinese Environmental Humanities (Chang) as well as chapters focused on Estonia, Finland, Norway, and other European nations in Framing the Environmental Humanities (Bergthaller and Mortensen).

On the whole, these publications and others characterize the Environmental Humanities as a forward-thinking field with old roots, stretching back to prehistoric cultures, yet bearing new seeds for an environmentally equitable future. At the same time, alongside the upsurge in scholarly books, Environmental Humanities research centers have germinated in Australia, Canada, Denmark, England, Germany, the Netherlands, Norway, South Africa, Sweden, Switzerland, the United States, and other parts of the world. Moreover, an increasing number of universities offer undergraduate and graduate degrees in the field. Founded in 2005, the University of Utah master's program features courses in field methods and thesis research. Based in Munich, Germany, the Rachel Carson Center's doctoral program in environment and society is run in conjunction with Ludwig Maximilian University and the Deutsches Museum, the largest museum of technology and science in the world. The florescence of the field has led scholars to 
investigate strategies for teaching the Environmental Humanities creatively as "an open, experimental, emergent space of possibilities — not to be locked down by an overly prescriptive canon or set of methodologies" (O’Gorman 458).

Environmental Humanities scholarship necessitates a solid grounding in the field's disciplinary roots, for example, in philosophy and literature. Transdisciplinary environmental scholars must acknowledge the disciplinary cornerstones of EH "while also creating space for something different to emerge from their imbrication” (Jørgensen and Ginn 497). An important aspect of the reflexive movement between disciplinarity and transdisciplinarity at the heart of the Environmental Humanities is language itself. How can environmental humanists describe the emergent phenomena of the Anthropocene? What language transformations are required to articulate experiences of the radical changes occurring constantly around - and within —all beings? To this end, since 2014, the Living Lexicon for the Environmental Humanities has called attention to the ways in which particular keywords - from absence and belonging to resilience and sacrifice - might push the field into "interesting directions that take seriously this dual imperative for critique and action" (Environmental Humanities para. 2, emphasis added). To be certain, a distinguishing feature of the field is its emphasis on balancing theory (critique) with practice (action).

The following critical review article introduces twelve dynamic developments in the Environmental Humanities beginning with animal and plant studies and ending with the wetland humanities. These Environmental Humanities specializations demonstrate the remarkable diversity of the field as scholars—resisting anthropocentrism—place greater emphasis on human and more-than-human voices in the Anthropocene. Some of these emergent focus areas, notably 
Symbiocene studies, have given rise to new lexicons to articulate the complex human-nature entanglements of our present era.

\section{Animal and Plant Studies}

Also known as anthrozoology, human-animal studies (HAS) emerged in the 1990s through the collaborative efforts of diverse scholars - anthropologists, biologists, geographers, historians, philosophers, psychologists, and others - with a common interest in the animal world.

Over the last thirty years, HAS has evolved as a discrete trajectory within the Environmental Humanities. Inherently transdisciplinary, the field explores the myriad complexities between humans and animals—wild, domestic, and feral—from various perspectives. Sometimes described more precisely as human-non-human-animal studies, HAS interrogates the very idea of the animal in light of the evolutionary reality that humans are also animals. The field thus aims to develop new ways of understanding animals and human-animal interactions. HAS researchers ask "why animals are represented and configured in different ways in human cultures and societies around the world; how they are imagined, experienced, and given significance; what these relationships might signify about being human; and what about these relationships might be improved for the sake of the individuals as well as the communities concerned" (Marvin and McHugh 2, emphasis original).

An integral aspect of HAS is the recognition that animals are part of human stories and histories but also have their own stories and histories. As agents in themselves, animals are intimately entangled with humans yet produce forms of meaning independent of ours. HAS researchers, accordingly, attend to issues of animal ethics, such as meat consumption, in the tradition of Peter Singer's landmark publication Animal Liberation (originally 1975). An 
example of a current topic of interest inhuman-animal studies is the Malayan pangolin (Manis spp.), a mammal regarded by some virus researchers as the vector for the Covid-19 pandemic.

In addition to human-animal studies, the field of human-plant studies (HPS) has taken shape over the last decade through the work of scholars such as philosopher Michael Marder and biologist Anthony Trewavas. Researchers in this field respond to the traditional Western characterization of plants-herbs, shrubs, and trees - as passive, sessile, and silent; as green backdrops to human affairs. Humans tend to think of plants in narrow utilitarian terms as foods, medicines, fibers, dyes, materials, ornaments, decorations, and so on. As the plant-focused version of human-animal studies, HPS field offers a transdisciplinary framework for understanding vegetal beings as intelligent, conscious, and capable subjects - as agents in their own right rather than solely as objects to be manipulated for human needs. Toward this end, the field draws from advances in the biological sciences (specifically plant cognition), social sciences (ethnobotany), philosophy (critical plant studies), history (botanical history), literary studies (phytocriticism), and other scholarly approaches to people-plant relationships. Like HAS, HPS also addresses ethical concerns, including the genetic manipulation of seeds and the possibility that plants experience pain (“Passive Flora?").

\section{Arctic and Antarctic Humanities}

The Arctic and the Antarctic are polar regions located at the northernmost and southernmost ends of the Earth, respectively. Whereas the Arctic includes parts of Scandinavia, Greenland, Russia, Canada, and the United States, the Antarctic comprises the continent of Antarctica and outlying areas. Containing over ninety percent of the world's ice, Antarctica is the planet's coldest and driest continent. In their beauty, ruggedness, and remoteness, both regions 
hold a prominent place in humankind's imagining of the planet. Yet, knowledge of the Arctic and Antarctic historically has been dominated by scientific observation and data collection rather than social science and humanities paradigms. Nevertheless, the profound impacts of climate change-visible in the dramatic loss of sea ice and snow cover-draw attention to the importance of political, social, cultural, humanistic, and arts-based approaches to addressing major issues in these regions. For instance, one-third of researchers participating in the Fourth International Polar Year - an intensive polar research program held between 2007-2008 — came from the social sciences and humanities. As a consequence, in recent years, the Arctic and Antarctic humanities have gained considerable momentum as polar specialties of the Environmental Humanities.

The Arctic humanities investigates the art, literature, and material culture associated with the Arctic, including the region's Indigenous people (Chukchi, Iñupiat, Saami, and others). This burgeoning area of the Environmental Humanities aims to counter the dominant view of Arctic knowledge as the domain of ice cores, climate data, and other scientific measures. The field, accordingly, approaches the Arctic environment and its people as subjects of transdisciplinary scholarship integrating aspects of culture, history, environment, science, and technology. An early study in the Arctic humanities is anthropologist Julie Cruikshank's book Do Glaciers Listen?, focusing on the glaciers of the Mount Saint Elias region at the junction of Alaska, the Yukon, and British Columbia. Examining accounts of glaciers by Indigenous people and European explorers, Cruikshank highlights a significant emphasis among Arctic humanistsclimate and climatic change. In this context, historian Sverker Sörlin has recently proposed the idea of the cryo-historical moment in which ice forms - and their loss due to the warming climate-embody the biospheric scale of change that has become symptomatic of the 
Anthropocene epoch. The Arctic, for Sörlin and other scholars, is central rather than peripheral to understanding global environmental concerns.

Comparably, the Antarctic has generated extensive cultural material and captivated the human imagination for eons. Before the first confirmed sightings of Antarctica by expeditions in 1820, Aristotle postulated the presence of a southern landmass while Ptolemy called the region “Terra Australis Incognita" or "unknown southern land." In the 1950s and '60s, humanistic Antarctic scholarship took shape through historical and geographical analyses of the Antarctic Treaty System, which legally designated the continent as a scientific reserve. Antarctic art and literature have resulted from both real and imagined encounters with the region. Literary works such as Kim Stanley Robinson's science fiction novel Antarctica critique dominant narratives of the continent as a resource base, an isolated outpost, a scientific reserve, and, more recently, an ecotourism icon. Like the Artic humanities, the Antarctic humanities considers competing depictions and imaginings of the polar region through various disciplinary stances. Especially with regard to climate change, humanities techniques are leveraged to enhance knowledge of this mysterious and misunderstood region. As such, the field acknowledges that "the Antarctic is a series of representations that are always selected, distilled, and packaged by humans" (Roberts et al. 14).

\section{Asian Environmental Humanities}

As an academic field, the Environmental Humanities has emerged predominantly from the English-language_or "Anglo-European"—contexts of North America, Europe, and Australia. Nonetheless, the world's geographically largest and most densely populated continent, Asia, abounds in diverse traditions connecting the humanities to the natural world-from the 
marine habitats of Timor-Leste and Indonesia to the mountains of Bhutan and grasslands of Mongolia. With its coastal super-cities and breakneck pace of industrialization, moreover, Asia has become acutely vulnerable to climate change, water and air pollution, biodiversity decline, and eco-disasters epitomized by the 1984 Bhopal Gas Tragedy in India. Yet, beyond the disciplines of anthropology and history, the Environmental Humanities has been relatively slow to gain a foothold in Asia. Through the dedication of environmental scholars, based both within and outside of the continent, the Asian environmental humanities is becoming a lively contributor to the global evolution of the field particularly in its regional emphasis on East Asia, South Asia, and Southeast Asia (Chang; Chu; Diamond; Southeast Asian Ecocriticism; Thornber).

Ecocritic Karen Thornber argues that scholars of Asia have much to contribute to "communicating the findings of scientists and social scientists to the broader public [while] promoting actual cultural and ecological change" (999). In the East Asian context, for instance, the essay collection Chinese Environmental Humanities (Chang) makes a distinct contribution to studies of sustainability, ecocriticism, ecocinema, ecomedia studies, ecoaesthetics, multispecies relations, and Buddhist ecological ethics vis-à-vis Chinese culture. Chang's book highlights the influence of Asian philosophies and religious traditions on the development of the Environmental Humanities. Chinese traditions are a source of non-Western terms, concepts, and perspectives, such as huanjing, translated as "environing" or "place-making" and suggesting ecological interconnectedness. In the Southeast Asian context, moreover, the edited volume Southeast Asian Ecocriticism (Ryan) explores human-elephant relations in Thailand, music videos produced by Indigenous communities in the Philippines, and the representation of plant 
life in Indonesian children's literature, among other topics. These kinds of studies are helping to propel the growth of the Environmental Humanities in Asia.

\section{Blue Humanities}

Covering 71 percent of the Earth's surface, oceans contain 97 percent of all the planet's water. Within the world's immense interconnected oceanic systems - collectively called the World Ocean or Global Ocean-marine species range in size from microscopic phytoplankton to enormous cetaceans such as the blue whale (Balaenoptera musculus), an animal that, growing one-hundred feet in length, is considered the largest to have ever lived. According to the National Oceanic and Atmospheric Administration, or NOAA, 91 percent of all marine species are scientifically unclassified and, additionally, about 80 percent of the Global Ocean remains unmapped. What's more, merely 3 percent of the Earth's water is fresh. Sequestered in glaciers, ice caps, soil, the atmosphere, and elsewhere, most fresh water is off limits; in fact, only 0.5 percent of all known water is both potable and accessible. Imagine if the world's water resources amounted to 100 liters (or 26.4 gallons): the usable portion would be only 0.003 liter $(0.0008$ gallon or one-half teaspoon). As these figures indicate, fresh water is a precious resource that humankind should avoid taking for granted. Scholarship in the blue humanities, consequently, reminds us of our interdependencies with water in all of its manifestations.

The blue humanities is an emerging specialism within the Environmental Humanities that focuses on water, hydrological systems, and aquatic life. Highlighting the increasingly aquatic orientation of ecological scholarship, the field views oceans and freshwater bodies-from deep sea zones and coral reefs to lakes and rivers - as sites of transdisciplinary inquiry (Campbell and Paye). Calling attention to the intimate-and intricate-relationships between humans, more- 
than-humans, and water, the blue humanities marks a shift from the terrestrial to the aquatic, particularly in anthropology, geography, history, and literary studies. Blue humanists refer to "the oceanic turn" as a shift toward critical and creative work that recognizes water as a physical agent and symbolic force (DeLoughrey). The issues investigated by blue humanists include climate change, rising sea levels, and ocean acidification in addition to lesser-publicized concerns over the impacts of underwater sonar on cetaceans and the implications of deep-sea mining. Scholars of the blue humanities, furthermore, examine the crucial role of technology in mediating relationships between people and water, especially the sea (Alaimo). A salient example of this issue is the deployment of manned submersibles over the last six decades to chart the Marianas Trench, the deepest part of the ocean.

\section{Emergency Humanities}

The Environmental Humanities is pivotal to understanding the Covid-19 pandemic and other emergencies in their cultural, historical, and ecological contexts. In 2020, in response to Covid-19, climate change intensification, catastrophic wildfires, and rampant species extinctions, the organizers of the Association for the Study of Literature and Environment, or ASLE, biennial symposium proposed the term emergency humanities to refer to a growing area of the Environmental Humanities focused on the manifold urgencies facing the biosphere today (Welling et al.). This very new scholarly field critically considers the contribution of the humanities to knowledge of Covid-19 and, more broadly, assesses the potential transformation of humanistic scholarship during times of urgency. Emergency humanists stress that "the humanities and the study of culture are indispensable, especially given the need for a critical 
approach to the [Covid-19] crisis and the measures taken in response to it" (Bachmann-Medick $80-81)$

Evolving in response to Covid-19, then, the emergency humanities could also be described synonymously as the pandemic humanities, resulting from the "pandemic turn" that is predicted to affect all areas of the humanities in coming years (Bachmann-Medick 78). Through critical approaches to history, culture, society, and technology, the humanities indeed have the capacity to stimulate new modes of thinking and doing in a post-corona world (BachmannMedick 82-83). In particular, the emergency humanities explores diverse topics including cultural and religious perceptions of emergencies; pragmatic and scientific solutions to crises; and ethical concerns arising during catastrophes. The emergency humanities, furthermore, acknowledges that human-nature relationships are the basis of Covid-19; and that pandemics impact marginalized groups disproportionately (Jørgensen and Ginn 498).

Scholarly interest in emergency is especially evident in the field of environmental history. As a case in point, the International Consortium of Environmental History Organizations, or ICEHO, recently launched "Epidemics and Ecologies: Reading in the Time of COVID-19." The project aims to stimulate more historical analyses of the linkage between human mobility, virus outbreaks, climate change, and biodiversity loss. Environmental-historical assessments of pandemics recognize that the transmission of infectious diseases accelerates as global ecological change increases (San Martín et al.).

\section{Empirical Ecocriticism}

Another intriguing development, specifically in connection to environmental literary studies, is known as empirical ecocriticism. This specialized branch of ecocriticism uses 
empirical methods — often involving quantitative and qualitative approaches to data — to study environmental texts of different kinds. Empirical ecocritics aim to test the central claims of the Environmental Humanities, namely that econarratives-for instance, climate poetry, fiction, and drama — encourage ethical attitudes and promote responsible actions toward the natural world.

The article "The Influence of Climate Fiction: An Empirical Survey of Readers" (Schneider-Mayerson) offers a lucid example of research in this emerging area. The author studied American readers of environmental literature to understand the wider effect of climate fiction, or cli-fi. To be certain, ecocritics tend to work from the premise that climate narratives build climate consciousness and inspire environmentally sensitive practices. But how do we know this? What's the evidence? How can this claim be tested? In order to gauge the validity of ecocriticism's fundamental assertions, Schneider-Mayerson performed a survey of readers, asking them questions such as "What lesson or message did you take away from this book, if any" (500). He concludes that climate fiction enables readers to envision climate scenarios while allowing the oftentimes abstract nature of climate change to become tangible for audiences. According to Schneider-Mayerson, climate narratives also give voice to anxiety, disorientation, helplessness, regret, loss, and other Anthropocene emotions. Environmental literature thus compels readers "to imagine potential futures and consider the fragility of human societies and vulnerable ecosystems" (Schneider-Mayerson 495). In this way, empirical ecocriticism encourages the application of social scientific methods to the analysis of environmental art, culture, literature, performance, and media. 


\section{Energy Humanities}

In 2019, 84 percent of global energy came from fossil fuels whereas 16 percent derived from low-carbon sources and renewables such as nuclear, hydropower, wind, solar, and biofuels. Of the fossil fuel, 33 percent was oil, 27 percent coal, and 24 percent gas (Ritchie and Roser). By the end of 2019, worldwide oil consumption reached 98.27 million barrels per day—an overall increase of 20 million barrels per day since 1998. In turn, fossil fuel consumption resulted in global energy-related carbon dioxide emissions estimated at a staggering 33 gigatonnes. During this time, moreover, the Asia-Pacific region, comprising East Asia, South Asia, Southeast Asia, and Oceania, had the greatest demand for oil in the world.

The implications of these statistics are of concern to scholars in the energy humanities, a growing area of the Environmental Humanities examining the complex entanglements between energy and society. First appearing in 2014, the term energy humanities refers to a growing body of scholarship applying humanities-based frameworks to energy research. Energy humanists assert that "today's energy and environmental dilemmas are fundamentally problems of ethics, habits, values, institutions, belief, and power-all traditional areas of expertise of the humanities and humanistic social sciences" (Boyer and Szeman, para. 6). The field explores, on the one hand, the production and consumption of energy and, on the other, artistic, literary, activist, and philosophical engagement with energy issues during the present age of intense human-driven change.

In many ways, the aims of the energy humanities overlap closely with those of the emergency humanities. In both its renewable and non-renewable forms, energy is an urgent concern that underlies climate change, species loss, habitat degradation, and other global catastrophes (Szeman and Boyer 9). The negative consequences of rampant energy consumption 
become glaringly evident during environmental disasters such as the Deepwater Horizon oil spill and Fukushima Daiichi nuclear disaster. Accordingly, the following objectives guide the work of energy humanists:

- to explore the basis of humanity's attachment to fossil fuels through a focus on histories of energy usage;

- to understand the ways in which energy shapes lives, cultures, societies, political structures, and human-nature relations; and

- to identify the spectrum of changes required for transitioning to a post-oil future that embraces renewable energy technologies. (Mišík and Kujundžić 10)

Researchers in the energy humanities also investigate the concept of petroculture, signifying the manifold ways in which oil has defined modernity and molded cultural life since the birth of the petroleum industry in 1850s (Wilson et al.).

\section{Extinction Studies}

We live in an age of extinction. Over the last five-hundred years, human activities have resulted in the extirpation of an estimated 680 vertebrate species in addition to countless invertebrates. From the Pinta giant tortoise of the Galapagos to the Spix's macaw of Brazil to the thylacine of Tasmania, extinction is not merely a vestige of the past but is an omnipresent urgency around the world today. Ecologists tell us that the current rate of species loss is up to one-thousand times greater than the natural, or background, extinction rates of the preceding ten million years. Also known as the Holocene or Anthropocene extinction, the sixth mass extinction unfolding around us is an ongoing, global event driven by the actions of Homo sapiens particularly since the start of the Industrial Revolution in the late-eighteenth century. Whereas 
volcanic eruptions, asteroid impacts, and oxygen depletion triggered the previous five mass extinctions, the Anthropocene extinction of the present is predominantly an outcome of human choices and behaviors.

More than five-hundred species of terrestrial mammals globally are on the verge of extinction and will most likely disappear in the next two decades. But extinction not only affects mammals. Indeed, plants, insects, fungi, lichens, microorganisms, deep sea creatures, and life forms yet to be identified by biologists all face this crisis. The United Nations Global Assessment Report on Biodiversity and Ecosystem Services estimates that one million species worldwide are at risk of extinction (Díaz). Yet, extinction not only pertains to individual species but also to the loss of populations of organisms (or what are called local extinctions). The demise of species or populations, in turn, diminishes the vitality of ecosystems as integrated wholes and sets in motion subsequent extinction events: "close ecological interactions of species on the brink tend to move other species toward annihilation when they disappear-extinction breeds extinction" (Ceballos et al. 13596, emphasis added).

These concerns inform extinction studies, a field investigating the aesthetic, cultural, ecological, emotional, ethical, social, and spiritual dimensions of extinction. The objective of this specialized area of the Environmental Humanities is to trace the values, beliefs, and world views that have led to the present catastrophe. Approaching extinction as both biological and cultural, scholars examine the ways in which societies recognize, understand, and respond to this urgency (Elmore 6). The editors of Extinction Studies: Stories of Time, Death, and Generations, the defining publication in this field, maintain that "there is no singular phenomenon of extinction; rather, extinction is experienced, resisted, measured, enunciated, performed, and narrated in a variety of ways to which we must attend" (Rose et al. 2-3). Extinction studies, accordingly, 
focuses on "understanding and responding to processes of collective death, where not just individual organisms, but entire ways and forms of life, are at stake" (Rose et al. 5).

\section{Medical-Environmental Humanities}

Tacuinum Sanitatis (Taqwìm as-Sihha or Maintenance of Health) is an eleventh-century Arab medical handbook that details the therapeutic properties of various foods and herbs. A version of the treatise from the late-fourteenth century features an illustration of the poisonous plant mandrake (Mandragora officinarum) beside the figures of a man and dog (Figure 1). Most noticeably, the image depicts the root mass of the mandrake as a human face with closed eyes. On the one hand, this curious portrayal—which critics might describe as an early instance of anthropomorphism, or the attribution of human characteristics to non-human beings-calls attention to the prevailing medical beliefs of the era. The medieval doctrine of signatures correlates the physical appearance of a plant part—root, leaf, stem, flower, seed, and so forth — to the therapeutic value of a species. In the illustration, the humanization of the mandrake's underground network signifies the strong effects of the root medicine on the mind. On the other hand, this evocative image offers a medieval foretaste of Charles Darwin's suggestion in the latenineteenth century that the brains of plants are located in their roots.

The mandrake illustration from Tacuinum Sanitatis provides an example of the kind of subject matter of interest to scholars in the medical-environmental humanities, or medecohumanities for short (Slovic et al.). The relationship between human, more-than-human, ecosystemic, and planetary health is the central concern of this nascent field. Bringing an environmental perspective to the medical humanities, the med-ecohumanities shares ground with the emergency humanities, discussed previously in this article, especially in terms of the 
coronavirus pandemic. Despite its devastating widespread impacts, Covid-19 has brought to light the dynamic interconnections between human and Earth health—between people, place, and planet. In this regard, the med-ecohumanities reflects developments in the "planetary health humanities," focused on the contribution of the arts, humanities, and social sciences to both human and environmental wellbeing (Lewis).

Although coined in the 1960s, the term medical humanities gained currency among Britain academics in the 1990s to designate a growing field exploring the relationship between the biomedical sciences and humanistic thinking. Emerging specifically from debates in bioethics, the medical humanities emphasizes the social dimensions of health, wellness, healing, illness, death, medicine, and the body. Medical humanists examine narratives of sickness, suffering, and recovery from diverse perspectives - cultural, historical, literary, philosophical, religious, and more. Since the 1990s, the field has evolved into an invaluable framework for training medical practitioners in the concepts and methods of the humanities and allied areas of the arts and social sciences (Fitzgerald and Callard).

The med-ecohumanities, therefore, deals with questions of health, environment, conservation, and human-nature interactions in an era of climate crisis. Possible topics of research include literary representations of contaminated environments in nineteenth-century British literature as well as performances of curative songs among Indigenous Amazonian communities. The med-ecohumanities investigates salient current issues such as the ecological origins of the coronavirus as well as historical subjects, as shown in the case of Tacuinum Sanitatis and the question of why medieval manuscripts represent medicinal species as humanplant hybrids. Ensuring a focus on health, wellbeing, healing, and embodiment in the Environmental Humanities, the field opens up dynamic new prospects for research. 


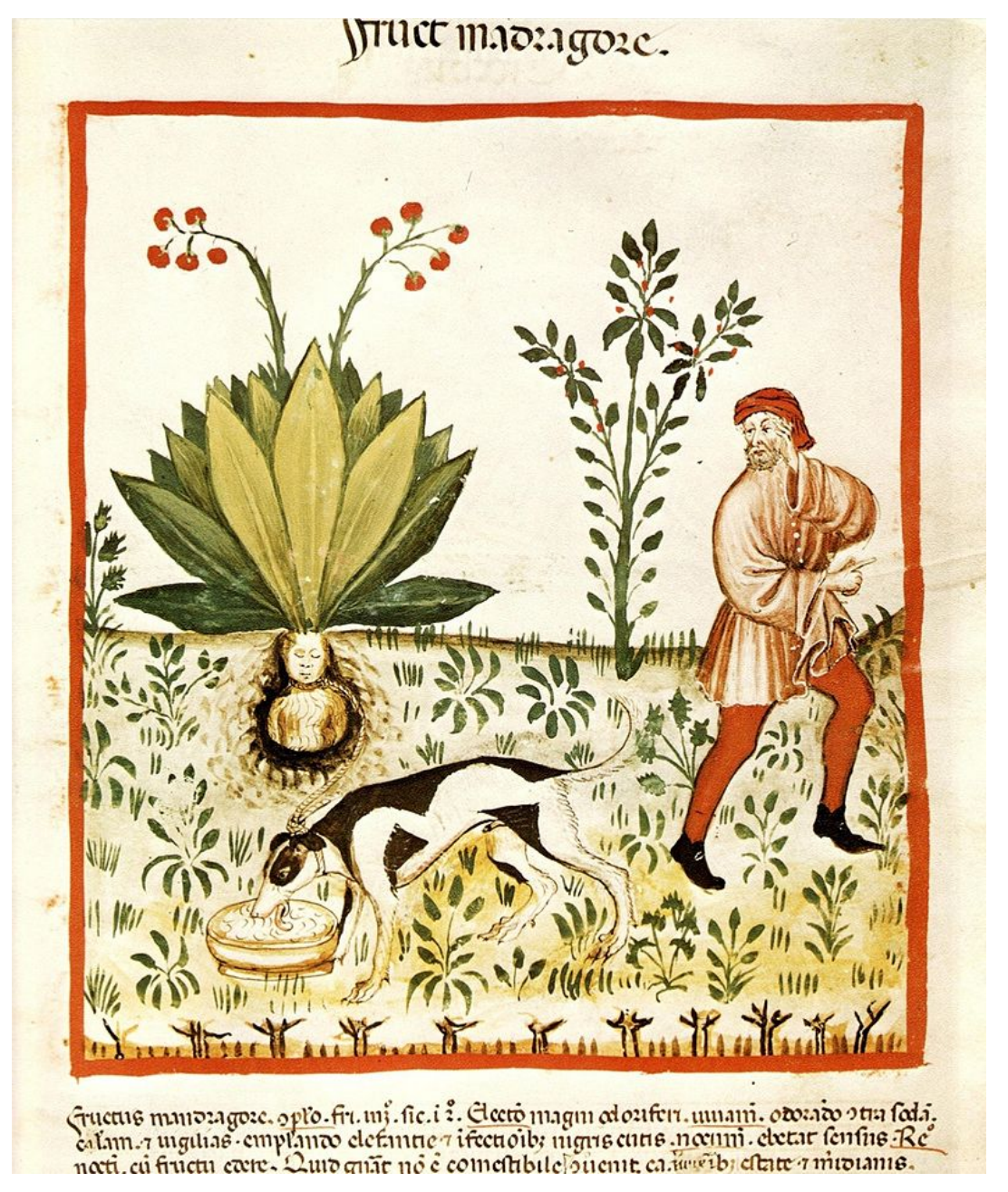

Figure 1.1

Mandrake (Mandragora officinarum) from Tacuinum Sanitatis manuscript (ca. 1390). Image credit: Wikimedia Commons (Hans Biedermann) (Public Domain)

\section{Paleoenvironmental Humanities}

Concerned with the deep time historical record, paleoarchaeology investigates human evolution through the fossil remains of chimpanzees, bonobos, gibbons, orangutans, gorillas, Homo sapiens, and other hominids. Paleoarchaeologists examine material evidence from a broad timeframe-from the emergence of human ancestors during the Miocene epoch around $15,000,000$ years ago to the end of the last ice age about 10,000 years ago. Deep time reflects 
Earth history; it is a sense of time that registers in millionennia (millions of years) rather than millennia (thousands of years) or centuries (hundreds of years). In 1785, geologist James Hutton proposed the concept of deep time after conducting detailed observations of soil erosion patterns in his native Scotland. In the early 1980s, the American nature writer John McPhee helped to popularize the concept by acknowledging its difficulty_or "obscure dimensions"—comprising geological periods so immense that "each has acquired its own internal time scale" (231). In reference to debates surrounding the Anthropocene, palaeobiologist Jan Zalasiewicz more recently has called our attention to "a peculiarity of geological time, which is that, at heart, it is simply time - albeit in very large amounts" (124, emphasis added).

Attentive to the complexities of deep time, then, the paleoenvironmental humanities $(\mathrm{PEH})$ is a new trajectory in the Environmental Humanities with only a handful of published studies to date (Hussain and Riede; Roddick). The field centers on the potential contribution of archaeology to the Environmental Humanities and, in particular, aims to address the relative lack of paleoarchaeological perspectives in humanistic studies of climate change. Developing the idea of human-climate relations, PEH considers the connections between human behaviors and climatic alteration in the context of ecological change across deep geological timescales. By offering a long-term view of human-climate interactions, the paleoenvironmental humanities addresses the dominant concerns of the Environmental Humanities, namely the Anthropocene, climate crisis, deep time, and human agency. PEH emphasizes the significance of deep time narratives - from hopeful stories of human adaptation to tragic ones of societal collapse-while, at the same time, developing compelling empirical evidence for environmental transformation. The field's overall objective is "to reframe the wider discourse on climate change in terms of our quickly expanding deep-time knowledge and to demonstrate that humans can neither be 
characterized as beings fundamentally divorced from nature" (Hussain and Riede 7). PEH, moreover, presents approaches for teaching concepts of time and temporality across the many disciplines that constitute the Environmental Humanities (Roddick).

Indeed, time and temporality are important to the study of the Environmental Humanities. While these concepts are sometimes used interchangeably, they in fact carry different meanings. On the one hand, time measures the movement from the past to the present and future. Much like a clock, watch, or calendar, time is an instrument that standardizes the passage of moments through the imposition of units (seconds, minutes, hours, days, months, years, decades, and so on). On the other hand, temporality is a philosophical premise denoting our perception and experience of time as well as its social construction. As a case in point, depending on their geographical location, Aboriginal Australian societies recognize between two and seven seasons, demonstrating a sense of temporality that differs markedly to that which underlies the AngloEuropean four seasons.

The aim of the paleoenvironmental humanities is to reinforce a deep time perspective in the Environmental Humanities through empirical examination of archaeological evidence. Considering that humans tend to have an innate aversion to deep time, this is a crucial undertaking. In her book Timefulness: How Thinking Like a Geologist Can Help Save the World (2018), geologist Marcia Bjornerud defines the term chronophobia as the human denial of deep time due to the existential dread and disorientation the concept causes. Most individuals, she argues, have little sense of planetary history, evolutionary timescales, and geological periods. In relation to climate change and the Anthropocene, the dangers of "temporal illiteracy" (Bjornerud 7) are real and immediate. In contrast to chronophobia, chronophilia is, literally, "the love of 
time" whereas timefulness is an outlook that strives to position the human in Earth history and promote deep time awareness.

\section{Symbiocene Studies}

The Anthropocene concept is not without its critics. Some environmental humanists assert that the idea, in conferring excessive agency to humankind, reinforces the anthropocentrism at the center of the global ecological crisis. Scholars indeed have urged the consideration of alternatives: Capitalocene, Homogenocene, Myxocene, Plantationocene, Planthroposcene, Thanatocene, and, even, unflatteringly, Bandwaggonocene (to call attention to the bandwagon phenomenon in environmental discourse whereby certain terms, after becoming fashionable, weaken in meaning). As a replacement for the Anthropocene, the Australian environmental philosopher Glenn Albrecht provokes the idea of the Symbiocene as an epoch of deeper symbiosis between humankind and the natural world. The Symbiocene focuses on the "mutually reinforcing life-reproducing forms and processes found in living systems" (Albrecht 102). Albrecht's proposal for the Symbiocene entails a novel vocabulary necessary to articulate what he calls Earth emotions. The new language of the Symbiocene enables us to speak of a future beyond the despair and desolation of the Anthropocene. Positioned within the Environmental Humanities, Symbiocene studies invites critical appraisals of these possibilities.

Albrecht is known for solastalgia, a concept referring to the psychological malaise resulting from ecological degradation. His study Earth Emotions defines solastalgia as "the pain or distress caused by the ongoing loss of solace and the sense of desolation connected to the present state of one's home and territory [...] the homesickness you have when you are still located within your home environment" (Albrecht 38-39). Albrecht opens the book with his 
ownsumbiography, defined as an autobiographical account of the experiences that collectively produce an individual's environmental values (13-25). He also distinguishes between the figures of the terraphthora (Earth destroyer) and the terranascia (Earth creator), highlighting the continuous friction between terraphthoric (destructive) and terranascient (creative) emotions vis-à-vis human experience of the Earth. He goes on to discern between the psychoterratic emotions (focused on the psyche and the environment) and the somaterratic emotions (focused on the body and the environment).

For Albrecht, negative Earth emotions include meteoranxiety (excessive worry over weather fluctuations), tierratrauma (bad environmental experiences with long-term psychological consequences), and terrafurie (the rage resulting from witnessing the destruction of nature) (85-88). In contrast, positive Earth emotions include eutierria (good Earth feeling) and endemophilia (love for that which is endemic to a place) (18). What's more, instead of anthropocentrism, sumbiocentrism recognizes "the centrality of the process of symbiosis in all of our deliberations" (Albrecht 101). As a result, in Albrecht's rather uplifting outlook, sumbiocracy can emerge as a mode of governance based on reciprocal relations between humans and other life forms.

\section{Wetland Humanities}

Among the most biodiverse and fertile environments on the planet, wetlands are crucial to sustaining all life. Including swamps, marshes, sloughs, bogs, billabongs, and other waterbodies, wetlands are ecosystems saturated with water long enough to give rise to specially adapted flora and fauna. Mixing water and earth, wetlands fall between the strict categories of the aquatic and terrestrial. These important ecosystems filter pollutants, protect human 
settlements from storms, and provide habitat for an array of organisms. Frequently compared to biological supermarkets, some wetlands produce ten times more biomass than a wheat field. The largest wetlands area in the world, Brazil's Pantanal of Mato Grosso, encompasses 200,000 square kilometers (77,000 square miles) and is almost as large as the whole United Kingdom. Nonetheless, wetlands of all sizes can be found across the globe. Indeed, many of the world's famous cities-New York, Washington D.C., Paris, London, Melbourne, and many otherswere built on swamps.

Despite their ecological primacy, wetlands have been drained, degraded, and reclaimed throughout history. In response to the rampant negative perception of swamps as sources of disease and discomfort, the wetland humanities explores human-swamp relations from artistic, cultural, historical, literary, philosophical, and psychological perspectives. About twenty-five years ago, environmental humanist Rod Giblett's Postmodern Wetlands inaugurated the wetland humanities with his call for the recognition of swamps as both biologically and cultural significant. The wetland turn in the Environmental Humanities counterbalances the field's predominant emphasis on rivers, lakes, and oceans, as evident in the blue humanities, discussed previously in this article. Recent work in the wetland humanities proposes the idea of a wetland culture signifying, on the one hand, cultural expressions (paintings, poems, performances, etc.) that closely involve swamps and, on the other, the ways in which swamps as non-human agents give rise to these cultural forms over time (Ryan and Chen).

\section{Conclusion}

This article has reviewed twelve current trajectories in the Environmental Humanities (EH) that collectively demonstrate the considerable diversity and timeliness of the field as 
scholars from a multitude of disciplines increasingly turn their attention to human-nature relations in the Anthropocene. The developments outlined here include animal and plant studies; Arctic and Antarctic humanities; Asian environmental humanities; blue humanities; emergency humanities; empirical ecocriticism; energy humanities; extinction studies; medicalenvironmental humanities (or med-ecohumanities); paleoenvironmental humanities; Symbiocene studies; and wetland humanities. Specializations such as the emergency humanities and medical environmental humanities have gained momentum in the context of the Covid-19 pandemic and the debate over its ecological origins. Other focus areas, namely Symbiocene studies, are devoted to envisioning alternatives to the despair of the Anthropocene and to enlivening possibilities for human-nature harmonization. Regardless of its bountiful permutations, the Environmental Humanities as a pluralistic transdisciplinary field continues to inspire constructive biocultural change, enabling scholars and the public alike to embrace practical sustainability, devise radical solutions, and cultivate hope for human-nature balance.

\section{Works Cited}

Alaimo, Stacy. "Introduction: Science Studies and the Blue Humanities." Configurations, vol. 27, no. 4, 2019, pp. 429-432, DOI: 10.1353/con.2019.0028.

Albrecht, Glenn. Earth Emotions: New Words for a New World. Cornell University Press, 2019.

Bachmann-Medick, Doris. "The Humanities - Marginalized after Corona?” 13 Perspectives on the Pandemic: Thinking in a State of Exception, edited by Rabea Rittgerodt, Walter De Gruyter, 2020, pp. 78-83. A De Gruyter Humanities Pamphlet.

Bergthaller, Hannes and Peter Mortensen, editors. Framing the Environmental Humanities. Brill, 2018. 
Bjornerud, Marcia Timefulness: How Thinking Like a Geologist Can Help Save the World. Princeton University Press, 2018.

Boschman, Robert and Mario Trono, editors. On Active Grounds: Agency and Time in the Environmental Humanities. Wilfrid Laurier University Press, 2019.

Boyer, Dominic and Imre Szeman. "The Rise of Energy Humanities: Breaking the Impasse." University Affairs, Feb. 12, 2014, https:/www.universityaffairs.ca/opinion/in-myopinion/the-rise-of-energy-humanities/. Accessed 13 Dec. 2020

Campbell, Alexandra and Michael Paye. "Water Enclosure and World-Literature: New Perspectives on Hydro-Power and World-Ecology." Humanities, vol. 9, no. 3, 2020, pp. 1-15, https://doi.org/10.3390/h9030106.

Ceballos, Gerardo et al. "Vertebrates on the Brink as Indicators of Biological Annihilation and the Six Mass Extinction." PNAS: Proceedings of the National Academy of Sciences of the United States of America, vol. 117, no. 24, 2020, pp. 13596-13602, https://doi.org/10.1073/pnas.1922686117.

Chang, Chia-ju, editor. Chinese Environmental Humanities: Practices of Environing at the Margins. Springer Nature, 2019.

Chu, Kiu-wai. "Ecocinema." Journal of Chinese Cinemas, vol. 10, no. 1, 2016, pp. 11-14, https://doi.org/10.1080/17508061.2016.1142728

Cruikshank, Julie. Do Glaciers Listen? Local Knowledge, Colonial Encounters, and Social Imagination. University of British Columbia Press, 2006.

DeLoughrey, Elizabeth. "The Oceanic Turn: Submarine Futures of the Anthropocene." Humanities for the Environment: Integrating Knowledge, Forging New Constellations of Practice, edited by Joni Adamson and Michael Davis, Routledge, 2017, pp. 242-258. 
Diamond, Catherine. "Whither Rama in the Clear-Cut Forest: Ecodramaturgy in Southeast Asia." Asian Theatre Journal, vol. 31, no. 2, 2014, pp. 574-593.

Díaz, Sandra et al. The Global Assessment Report on Biodiversity and Ecosystem Services: Summary for Policymakers. Intergovernmental Science-Policy Platform on Biodiversity and Ecosystem Services (IPBES), 2019.

Elmore, Jonathan. "Introduction: The Urgency of Story During the Sixth Mass Extinction." Fiction and the Sixth Mass Extinction: Narrative in an Era of Loss, edited by Jonathan Elmore, Lexington Books, 2020, pp. 1-12.

Emmett, Robert and David Nye. The Environmental Humanities: A Critical Introduction. The MIT Press, 2017.

Environmental Humanities. "Living Lexicon for the Environmental Humanities: AbsenceWit(h)nssing. " Environmental Humanities, 2020.

Fitzgerald, Des and Felicity Callard. "Entangling the Medical Humanities." Edinburgh Companion to the Critical Medical Humanities, edited by Anne Whitehead and Angela Woods, Edinburgh University Press, 2016, pp. 35-49.

Frawley, Jodi and Iain McCalman, editors. Rethinking Invasion Ecologies from the Environmental Humanities. Routledge, 2014.

Giblett, Rod. Environmental Humanities and the Uncanny: Ecoculture, Literature and Religion. Routledge, 2019.

---. Environmental Humanities and Theologies: Ecoculture, Literature and the Bible. Routledge, 2018.

---. Postmodern Wetlands: Culture, History, Ecology. Edinburgh University Press, 1996. 
Gladwin, Derek, editor. Ecological Exile: Spatial Injustice and Environmental Humanities. Routledge, 2018.

Heise, Ursula et al., editors. The Routledge Companion to the Environmental Humanities, 1st edition. Routledge, 2017.

Hussain, S. T. and F. Riede. "Paleoenvironmental Humanities: Challenges and Prospects of Writing Deep Environmental Histories.” WIREs Climate Change, vol. 11, no. e667, 2020, pp. 1-18, https://doi.org/10.1002/wcc.667.

International Bio-Logging Society. "News: Covid-19 Bio-Logging Initiative.” https://www.biologging.net/\#about. Accessed 13 Dec. 2020.

Iovino, Serenella et al., editors. Italy and the Environmental Humanities. University of Virginia Press, 2018.

IUCN. "European Bison Recovering, 31 Species Declared Extinct - IUCN Red List." https://www.iucn.org/news/species/202012/european-bison-recovering-31-speciesdeclared-extinct-iucn-red-list. Accessed 13 Dec. 2020.

Jørgensen, Dolly and Franklin Ginn. "Environmental Humanities: Entering a New Time." Environmental Humanities, vol. 12, no. 2, 2020, pp. 496-500, https://doi.org/10.1215/22011919-8623252

Kelly, Jason M. et al., editors. Rivers of the Anthropocene. University of California Press, 2017.

Lewis, Bradley. "Planetary Health Humanities-Responding to Covid Times." Journal of Medical Humanities, 2020, https://doi.org/10.1007/s10912-020-09670-2

Marder, Michael. Plant-Thinking: A Philosophy of Vegetal Life. Columbia University Press, 2013. 
Marvin, Garry and Susan McHugh. "In It Together: An Introduction to Human-Animal Studies." Routledge Handbook of Human-Animal Studies, edited by Garry Marvin and Susan McHugh, Routledge, 2014, pp. 1-9.

McPhee, John. Basin and Range. Farrar, Straus and Giroux, 1982.

Mišík, Matúš and Nada Kujundžić. "Introduction." Energy Humanities. Current State and Future Directions, edited by Matúš Mišík and Nada Kujundžić, Springer Nature, 2021, pp. 1-21.

O'Gorman, Emily, et al. "Teaching the Environmental Humanities.” Environmental Humanities, vol. 11, no. 2, 2019, pp. 427-460, https://doi.org/10.1215/22011919-7754545.

Oppermann, Serpil and Iovino Serenella, editors. Environmental Humanities: Voices from the Anthropocene. Rowman \& Littlefield International, 2017.

Ray, Sarah Jaquette and Jay Sibara, editors. D-isability Studies and the Environmental Humanities: Toward an Eco-Crip Theory. University of Nebraska Press, 2017.

Ritchie, Hannah and Max Roser. "Energy." Our World in Data. https://ourworldindata.org/energy. Accessed 31 Dec. 2020.

Roberts, Peder et al. "Antarctica: A Continent for the Humanities." Antarctica and the Humanities, edited by Peder Roberts et al., Palgrave Macmillan UK, 2016, pp. 1-23.

Robinson, Kim Stanley. Antarctica. Harper Voyager, 1997.

Roddick, Andrew P. "The Paleoenvironmental Humanities: Climate Narratives, Public Scholarship, and Deep Futures." Current Swedish Archeology, vol. 26, 2018, pp. 79-85, https://doi.org/10.37718/CSA.2018.07 
Rose, Deborah Bird et al. "Introduction: Telling Extinction Stories.” Extinction Studies: Stories of Time, Death, and Generations, edited by Deborah Bird Rose et al., Columbia University Press, 2017, pp. 1-17.

Rutz, Christian, et al. "Covid-19 Lockdown Allows Researchers to Quantify the Effects of Human Activity on Wildlife." Nature Ecology and Evolution, vol. 4, no. 9, 2020, pp. 1156-1159, https://doi.org/10.1038/s41559-020-1237-z

Ryan, John Charles. "Passive Flora? Reconsidering Nature's Agency through Human-Plant Studies." Nature and Sustainability Beyond Humanism: A Reader in Environmental Anthropology, edited by Sarah Osterhoudt and Kalyanakrishnan Sivaramakrishnan, University of Washington Press, forthcoming.

---, editor. Southeast Asian Ecocriticism: Theories, Practices, Prospects. Lexington Books, 2017.

Ryan, John Charles and Li Chen, editors. Australian Wetland Cultures: Swamps and the Environmental Crisis. Lexington Books, 2019.

San Martín, William et al. "Epidemics and Ecologies: Reading in the Time of Covid-19." http://www.iceho.org/reading-in-the-time-of-covid-19. . Accessed 30 Dec. 2020.

Schneider-Mayerson, Matthew. "The Influence of Climate Fiction: An Empirical Survey of Readers." Environmental Humanities, vol. 10, no. 2, 2018, pp. 473-500, https://doi.org/10.1215/22011919-7156848

Singer, Peter. “Animal Liberation.” Animal Rights: The Changing Debate, edited by Robert Garner, Macmillan Press, 1996, pp. 7-18.

Slovic, Scott et al., editors. The Bloomsbury Handbook to the Medical-Environmental Humanities. Bloomsbury, 2022. 
Sörlin, Sverker. "Scaling the Planetary Humanities: Environmental Globalization and the Arctic." The Routledge Companion to the Environmental Humanities, edited by Ursula Heise et al., 1st edition, Routledge, 2017, pp. 449-458.

Szeman, Imre and Dominic Boyer. "Introduction: On the Energy Humanities." Energy Humanities: An Anthology, edited by Imre Szeman and Dominic Boyer, Johns Hopkins University Press, 2017, pp. 1-14.

Thornber, Karen. "Literature, Asia, and the Anthropocene: Possibilities for Asian Studies and the Environmental Humanities." The Journal of Asian Studies, vol. 73, no. 4, 2014, pp. 989 1000, doi:10. 1017/S002191 1814001569.

Trewavas, Anthony. Plant Behaviour and Intelligence. Oxford University Press, 2014.

Welling, Bart et al. "A Nearly Carbon Neutral Virtual Symposium.” https://www.asle.org/stayinformed/asle-news/humanities-on-the-brink-energy-environment-emergency-asle-2020virtual-symposium/. Accessed 30 Dec. 2020.

Wilson, Sheena et al. "On Petrocultures: Or, Why We Need to Understand Oil to Understand Everything Else.” Petrocultures: Oil, Politics, Culture, edited by Sheena Wilson et al., McGill-Queen's University Press, 2017, pp. 3-19.

Zalasiewicz, Jan. "The Extraordinary Strata of the Anthropocene.” Environmental Humanities:

Voices from the Anthropocene, edited by Serpil Oppermann and Serenella Iovino, Rowman \& Littlefield, 2017, pp. 115-131.

\section{Bionote:}

John Charles Ryan is Adjunct Associate Professor at Southern Cross University, Australia, and Adjunct Senior Research Fellow at Nulungu Institute, Notre Dame University, Australia. His research focuses on Aboriginal Australian poetry, environmental humanities, ecopoetics, and critical plant studies. His recent work includes the books Introduction to the Environmental Humanities (Routledge, 2021, authored with J. Andrew Hubbell); The Mind of Plants: 
Narratives of Vegetal Intelligence (Synergetic, 2021, edited with Monica Gagliano and Patrícia Vieira); and Nationalism in India: Texts and Contexts (Routledge, 2021, edited with Debajyoti Biswas). He can be reached at john.c.ryan@scu.edu.au

ORCID ID: https://orcid.org/0000-0001-5102-4561

\section{Open Access:}

This article is distributed under the terms of the Attribution-NonCommercial 4.0 International (CC BY-NC 4.0) (https://creativecommons.org/licenses/by/4.0/) which permits any use, reproduction and distribution of the work without further permission provided the original work is attributed as specified on the Transcript: An e-Journal of Literary and Cultural Studies.

For more information log on to http://thetranscript.in/

\section{Conflict of Interest Declaration:}

The author declared no potential conflicts of interest about the research, authorship and publication of this article.

(C) Author 